\title{
Executive functioning independently predicts self- rated health and improvement in self-rated health over time among community-dwelling older adults
}

\section{Joanna Edel McHugh \& Brian A Lawlor}

To cite this article: Joanna Edel McHugh \& Brian A Lawlor (2016) Executive functioning independently predicts self-rated health and improvement in self-rated health over time among community-dwelling older adults, Aging \& Mental Health, 20:4, 415-422, DOI: 10.1080/13607863.2015.1018866

To link to this article: $\mathrm{http}: / / d x . d o i . o r g / 10.1080 / 13607863.2015 .1018866$

Published online: 16 Mar 2015.

Submit your article to this journal ๘

Џ Article views: 64

View related articles 주

View Crossmark data $\asymp$ 


\title{
Executive functioning independently predicts self-rated health and improvement in self-rated health over time among community-dwelling older adults
}

\author{
Joanna Edel McHugh* and Brian A Lawlor \\ TRIL Centre, Trinity College Institute of Neuroscience, Trinity College Dublin, Dublin, Ireland
}

(Received 29 September 2014; accepted 8 February 2015)

\begin{abstract}
Objectives: Self-rated health, as distinct from objective measures of health, is a clinically informative metric among older adults. The purpose of our study was to examine the cognitive and psychosocial factors associated with self-rated health.

Methods: 624 participants over the age of 60 were assessed at baseline, and of these, 510 were contacted for a follow-up two years later. Measures of executive function and self-rated health were assessed at baseline, and self-rated health was assessed at follow-up. We employed multiple linear regression analyses to investigate the relationship between executive functioning and self-rated health, while controlling for demographic, psychosocial and biological variables.

Results: Controlling for other relevant variables, executive functioning independently and solely predicted self-rated health, both at a cross-sectional level, and also over time. Loneliness was also found to cross-sectionally predict self-rated health, although this relationship was not present at a longitudinal level.

Conclusion: Older adults' self-rated health may be related to their executive functioning and to their loneliness. Self-rated health appeared to improve over time, and the extent of this improvement was also related to executive functioning at baseline. Self-rated health may be a judgement made of one's functioning, especially executive functioning, which changes with age and therefore may be particularly salient in the reflections of older adults.
\end{abstract}

Keywords: older adults; executive functioning; self-rated health; functional status; longitudinal

Perceptions of one's own health constitute a multidimensional and holistic consideration (Idler \& Benyamini, 1997). Self-rated health relates to awareness of one's own body, symptoms, functional status and received diagnoses (Kaplan et al., 1996). According to Singh-Manoux et al. (2006), asking participants to rate their own health taps into six factors; age, early life and familial history of illness, socio-demographic variables, psychosocial wellbeing, health behaviours, and objective measures of health and disease. Self-rated health is a valuable tool for clinicians, since it has great predictive power, and is associated with mortality and morbidity outcomes even when functional status, depression and co-morbidities are accounted for, such that based on a meta-analysis of 20 published prospective cohort studies, overall individuals with 'poor' self-rated health were found to have a twofold (relative risk of 1.92) higher mortality risk than those with 'excellent' self-rated health (DeSalvo, Bloser, Reynolds, $\mathrm{He}, \&$ Muntner, 2006). Self-rated health can predict functional decline among older adults over time, with a 2.4 times risk of physical deterioration over six years in individuals with poor self-rated health compared to those with excellent health (Idler \& Kasl, 1995).

This relationship suggests that ratings of health may relate to functional status and therefore reflect health as the ability to function effectively and independently perform daily chores and self-care activities (Lawton \& Brody, 1969). Since the most salient outcome of poor health in late life is a decline in functioning, it would make sense that older adults may equate their health with their functional abilities, i.e. with what they can and cannot do.

As well as predicting overall functioning, self-rated health has previously been shown to predict cognition and cognitive decline (Anstey \& Christensen, 2000; Anstey, Luszcz, Giles, \& Andrews, 2001; Carmelli, Swan, LaRue, \& Eslinger, 1997; Earles, Conner, Smith, \& Park, 1997), specifically processing speed (Hultsch, Hammer, \& Small, 1993), although the relationship may be confounded by age and education level (Anstey, Stankov, \& Lord, 1993; Salthouse, Kausler, \& Saults, 1990).

However, there are grounds to hypothesise that the directionality of this relationship may be the reverse; that certain aspects of cognitive functioning may in fact predict self-rated health. It has been suggested that the selfrated health metric is meaningful only in populations without cognitive impairment, because it requires the execution of cognitive processes (Walker, Maxwell, Hogan, \& Ebly, 2004). Attentional capacities in childhood have also previously been found to predict self-rated health in adulthood (Kubzansky, Buka, \& Martin, 2009), indicating that there may indeed be some causal relationship between cognitive functioning and self-rated health status over the lifespan.

Specifically, it is possible that executive functioning could predict self-rated health among older adults.

*Corresponding author. Email: mchughje@tcd.ie 
Executive functioning governs the planning, co-ordinating, sequencing and monitoring of other cognitive functions (Salthouse, Atkinson, \& Berish, 2003). As such it makes sense that, physicality aside, daily functioning is governed by executive functioning. Age-related cognitive deficits are purported to be due to frontal cortical deterioration, which is largely reflected in executive dysfunction (Albert \& Kaplan, 1980). Executive functioning in older adults is a strong predictor of independent living capability (Cahn-Weiner, Boyle, \& Malloy, 2002; Grigsby, Kaye, Baxter, Shetterly, \& Hamman, 1998). Executive functioning may also impact upon self-rated health due to its role in engagement with health-related behaviours, such as taking exercise, medication adherence and planning nutritious meals (Kuo \& Lipsitz, 2004).

When assessing the potential relationship between executive functioning and self-rated health, it is important to account for potentially confounding psychosocial factors. Burke et al. (2011) emphasise the role of stress in determining self-rated health status, and stress reactivity is pre-frontally mediated, as is executive dysfunction (Sturm \& Willmes, 2001), which could potentially confound any relationship between executive functioning and self-rated health status. Similarly, depression and executive functioning may be linked as part of a larger 'depression-executive dysfunction syndrome' (Alexopoulos, Kiosses, Klimstra, Kalayam, \& Bruce, 2002). Anxiety (Liavaag, Dorum, Fosse, Trope, \& Dahl, 2009), social support, (White, Philgene, Fine, and Sinha, 2009) personality (Duberstein et al., 2003) and loneliness (Nummela, Soppanen, \& Uutela, 2011) have all previously been found to have an association with self-rated health, and as such may need to be considered when investigating potential links between executive functioning and self-rated health. On the other hand, a study investigating executive function among other facets of function in a sample of older adults found recently that it was not linked to selfrated health (Rouch et al., 2014).

In the current study, we wished to investigate a potential relationship between a measure associated with executive functioning (the trail making test), and self-rated health, when relevant biopsychosocial variables are controlled for. Self-rated health is distinct from objective measures of health and therefore potentially reflects some other aspect of functioning. We predict that executive function predicts self-rated health, since reflection and assessment capabilities are required to make a useful judgement of one's own health. The trail making test (Lezak, Howieson, \& Loring, 2004) is a psychometric test of executive functioning, as distinct from lower-order cognitive processes such as information processing speed, since it measures mental flexibility and divided attention. It is generally accepted that scores on the trail making test provide an index of overall executive functioning status (Arbuthnott \& Frank, 2000).

We also wanted to see if a predictive relationship was observed between executive functioning at baseline and the change in self-rated health over time. Change in selfrated health has been investigated previously, and global self-rated health is thought to typically decrease over time in longitudinal analyses (Sargent-Cox, Anstey, \& Luszcz, 2010). However, other researchers state that self-rated health is inherently dynamic, incorporating many timespecific factors, and as such can only be expected to fluctuate significantly over time, rather than change in any meaningful way (Han et al., 2005). A secondary aim of this study was then to investigate whether executive function at baseline may predict changes in self-rated health over time, which, since executive function typically deteriorates with age, would explain Sargent-Cox's related finding of a general decrease in self-rated health. If this relationship is not found, it is possible that the theory put forward by Han and colleagues more accurately reflects the nature of self-rated health.

\section{Methods \\ Participants}

A convenience sample of 624 men and women aged $\geq 60$ years underwent a baseline comprehensive geriatric assessment at the TRIL (Technology Research for Independent Living) Centre between August 2007 and May 2009. These were a convenience research sample and not representative of the population. The sample is described elsewhere in further detail (Romero-Ortuno, Cogan, Fan, \& Kenny, 2010). In order to participate, individuals had to be over 60 , not medically unwell, able to walk independently (or with a stick or frame), able to attend the hospital for assessment, and able to provide informed consent for research.

A follow-up telephone-based geriatric assessment was completed by 510 participants approximately two years later (attempts were made initially to contact the entire sample of 624 individuals; 30 had passed away, 37 were not contactable, and of the remaining 557 individuals, 510 were successfully contacted. Resource constraints prevented clinic staff from making further attempts to contact the remaining 47 original participants, and so the analysis here presented is based on results from 510 individuals).

This telephone-based assessment acted as a precursor to an invitation to return to the clinic to participate in a more involved physical and psychosocial follow-up assessment (although this more comprehensive assessment is not discussed here). All baseline assessments took place in the hospital, but at follow-up, home visits were offered to individuals who were unable to attend the hospital at this point for assessment.

The protocol of the follow-up assessment was a reduced version of the baseline, since resources were limited at the time of follow-up. Five hundred and ten participants were first contacted via telephone by a clinical nurse manager and received a brief telephone assessment. During this telephone assessment, information on self-rated health was collected. Demographic information (age, gender, education level, socio-economic status) and executive functioning and psychosocial functioning data were made available from the baseline data-set.

The majority of participants $(66.8 \%)$ were self-referrals/volunteers from the community or articles in the local 
media; the rest $(33.2 \%)$ were referrals from health professionals for further assessment. All participants were community dwelling, medically stable (i.e. no acute infection, stroke, or myocardial infarction), able to walk independently (with or without aids), and able to provide written informed consent, at both baseline and follow-up. Participants were not asked to stop any of their usual medications, fast, or modify lifestyle habits before either assessment. The mobility criterion was relaxed for follow-up and if participants were not able to attend the clinic, the clinical research nurses performed home-based assessments. For the purposes of the following analyses, individuals who had a mini mental state examination (Folstein, Folstein, \& McHugh, 1975) score of 23 or less were omitted, leading to the removal of data pertaining to 48 individuals, since this is likely to indicate cognitive impairment in the (information removed for review) population (Cullen et al., 2005). It is possible that individuals with a cognitive impairment may not be able to sufficiently reflect upon their self-rated health and we wanted to investigate a relationship between executive function and self-rated health in a cognitively intact population in this instance.

Ethical approval was obtained from the committee at the Adelaide, Meath \& National Children's Hospital \& St James's Hospital Research Ethics Committee. All participants gave written informed consent before inclusion in the study.

\section{Design}

The study was a longitudinal observational study, with participants interviewed at the hospital at baseline, by a geriatric medical, psychiatric and research psychologistled team. All participants underwent a structured clinical assessment at two timepoints, which included a medical and falls risk assessment by physicians, completion of frailty-related measures, and a number of psychosocial self-reported measures. The telephone interview in the interim was made to invite individuals back to the clinic for the follow-up assessment but also to gather data in its own right, including the self-rated health data.

\section{Measures}

Age, gender, education level attained (some primary, completed primary, some secondary, leaving certificate, college or university, postgraduate qualification), smoking status (active, ex or non-smoker), hours of exercise per week (defined as time spent in any sporting activity, jogging, walking, swimming, cycling, gardening, or other sporting or fitness related activity), alcohol intake (categorised as never drinks, occasionally drinks, frequently drinks, or daily drinks), activities of daily living and instrumental activities of daily living (Lawton \& Brody, 1969), and the Charlson co-morbidity index, which provides a score based on the number of co-morbidities a participant has been told they have (Charlson, Pompei, Ales, $\&$ MacKenzie, 1987). The score predicts the 10-year mortality for a patient who may have a range of comorbid conditions, such as heart disease or cancer (a total of 22 conditions are included in the index). Each condition is assigned a score of $1,2,3$ or 6 , which are weighted scores dependent on the risk of dying associated with this condition. Scores are summed and the individual is given a total score, which predicts mortality.

Personality was measured using the neuroticism and the extraversion subscales of the Eysenck Personality Questionnaire (revised; EPQ-R; Eysenck \& Eysenck, 1991). Each subscale uses 24 items to assess a dimension of personality. Extraversion reflects sociability or talkativeness, while neuroticism reflects susceptibility to experiencing psychological distress. Both scales have previously been found to be both reliable and valid (Alexopoulos \& Kalaitzidis, 2004). In the current cohort, internal consistency was found to be acceptable (for extraversion Cronbach's alpha was 0.715 , and for neuroticism it was 0.742).

Depressive symptomatology was assessed using the Center for Epidemiological Studies depression scale (CESD 8; Radloff, 1977). Participants are given a score of 0-8 depending on whether they indicate presence or absence of 8 depressive symptoms, and scores over 7 indicate presence of case level depression. The CESD has previously been shown to have sound psychometric properties (Radloff, 1977); however, the internal consistency of the scale in the current cohort was relatively low (Cronbach's alpha $=0.399)$.

Anxiety symptoms were assessed using the Hospital Anxiety and Depression Scale Anxiety subscale (HADS A; Zigmond \& Snaith, 1983) which uses seven items to assess anxiety and gives a score of $0-21$, with scores of above 11 indicating case level anxiety. The HADS A has previously been shown to have good psychometric properties (Woolrich, Kennedy, \& Tasiemski, 2006) and internal consistency was acceptable in the current cohort $($ Cronbach's alpha $=0.775)$.

Social support networks were assessed using the Lubben social network scale (Lubben \& Gironda, 2004) which assesses availability of social support from friends, family and neighbours, and demonstrates good psychometric properties (Lubben \& Gironda, 2004; Lubben et al., 2006) and in the current cohort internal consistency was high (Cronbach's alpha $=0.831$ ).

Perceived stress was assessed using the perceived stress scale (Cohen, Kamarck, \& Mermelstein, 1983), which yields a score of $0-40$ on 10 items and has good psychometric properties (Cohen \& Williamson, 1988), and in the current cohort internal consistency was acceptable (Cronbach's alpha $=0.744)$.

Finally, loneliness was measured using the de Jong scale of loneliness, which assesses social and emotional, as well as total, loneliness (de Jong Gierveld \& Tilburg, 2006) using six items. Both reliability and validity of the de Jong loneliness scale are at acceptable levels (de Jong Gierveld \& Tilburg, 2006) but in the current cohort were marginally below standard acceptable levels of internal consistency (Cronbach's alpha $=0.632$ ).

\section{Self-rated health}

Participants were asked to rate their own health at baseline and at the interim telephone interview. The clinical 
research nurse team member asked participants 'on a scale of 1 to 10 , with 1 being the worst and 10 being the best, how would you rate your own health?' Participants then gave a response of $1-10$. This is a numeric verbal rating scale and the format in which participants are asked to rate their own health has previously been shown to have little effect on their responses (Idler \& Benyamini, 1997; Juerges, Avendano, \& Mackenbach, 2007). The self-rated health variable during the interim phone call is the only variable we collected data on at this wave of data collection. All other variables in the current analysis relate to the first wave of data collection.

\section{Trail making test}

Trail making test (TMT; Lezak et al., 2004) was performed to measure attention, divided attention and psychomotor speed. The trail making test is a standard test of executive function which has two parts; A and B. Part A consists of numbers $1-25$ in circles placed randomly upon a sheet of paper. It requires participants to draw a line from number 1 through to number 25 without lifting the pen from the exercise sheet. Part B contains both numbers and letters and requires participants to alternate between connecting lines from letter to number to letter to number, etc. Both parts are timed using a stopwatch. A pure measure of executive functioning is derived by subtracting the score (time taken to complete in milliseconds) from part $A$, which reflects psychomotor speed, from the score of part B. The trail making test has high inter-rated reliability (Fals-Stewart, 1992) and validity (Gaudino, Geisler, \& Squires, 1995). The metric of interest in the current study is the pure measure of executive functioning, Trail making test $\mathrm{B}$ minus $\mathrm{A}$.

\section{Data analysis}

We calculated an attrition weight to apply to the longitudinal data, based on age, gender, Mini Mental State Examination scores (Folstein et al., 1975), frailty (calculated according to the Fried criteria (Fried et al., 2001), education level and referral source. This weight was created to account for the drop-outs experienced at follow-up. The weight applied to the data did not make a significant difference to results. This implies that the cohort involved at follow-up did not differ significantly from the cohort involved at baseline. Nevertheless, the weight was retained during all further analyses.

Descriptive statistics were first performed to describe the cohort in terms of their demographics and biopsychosocial profile. To evaluate the purported predictors of selfrated health at baseline, multiple linear regression models were used. The longitudinal analysis also used multiple linear regression with change in self-rated health over time as the dependent variable.

\section{Results}

In order to first characterise the cohort, we performed descriptive statistical analyses on the data (see Table 1).
Table 1. Descriptive statistics pertaining to the TRIL research cohort, detailing relevant predictive variables, SRH follow-up (self-rated health at follow-up) and $\delta \mathrm{SRH}$ (change in self-rated health over time).

\begin{tabular}{|c|c|c|}
\hline & Mean & $\mathrm{CI}_{95}$ \\
\hline Age & 72.75 & $72.18,73.32$ \\
\hline Gender & $\begin{array}{l}31.4 \% \text { male } \\
68.6 \% \text { female }\end{array}$ & \\
\hline NACI & 1.99 & $1.83,2.15$ \\
\hline ADL & 22.45 & $22.3,22.6$ \\
\hline IADL & 25.55 & $25.34,25.76$ \\
\hline Education level & $\begin{array}{l}1.5 \% \text { none } \\
29 \% \text { primary } \\
30.2 \% \text { secondary } \\
22 \% \text { diploma/certificate } \\
12.4 \% \text { college/university } \\
4.9 \% \text { postgraduate }\end{array}$ & \\
\hline LSNS & 46.57 & $45.54,57.6$ \\
\hline DJ Total & 1.35 & $1.23,1.47$ \\
\hline Neuroticism & 10.01 & $9.64,10.38$ \\
\hline Extraversion & 11.53 & $11.2,11.86$ \\
\hline CESD 8 & 1.79 & $1.63,1.95$ \\
\hline HADS A & 5.41 & $5.11,5.71$ \\
\hline PSS & 9.32 & $8.75,9.89$ \\
\hline Smoking & $\begin{array}{l}46.3 \% \text { never smoked } \\
44.3 \% \text { ex-smokers } \\
9.5 \% \text { active smokers }\end{array}$ & \\
\hline Alcohol intake & $\begin{array}{l}27.7 \% \text { never drink } \\
29.9 \% \text { occasionally drink } \\
26.7 \% \text { frequently drink } \\
15.8 \% \text { daily drink }\end{array}$ & \\
\hline Hours PE week & 5.61 & $5.31,5.91$ \\
\hline SRH Baseline & 6.84 & $6.68,7$ \\
\hline SRH follow-up & 7.58 & $7.43,7.73$ \\
\hline$\delta \mathrm{SRH}$ & 0.8056 & $0.56,1.06$ \\
\hline
\end{tabular}

Note: NACI (non-age-adjusted Charlson comorbidity index), ADL (activities of daily living), IADL (instrumental activities of daily living), education level, LSNS (Lubben social network scale score), DJ Total (de Jong total loneliness score), neuroticism, extraversion, CESD 8 (Centre for Epidemiological Studies Depression scale), HADS A (Hospital Anxiety and Depression Scale Anxiety subscale score), PSS (perceived stress scale score), smoking behaviour, alcohol intake, hours PE week (hours of exercise per week), SRH baseline (self-rated health at baseline), SRH follow-up (self-rated health at follow-up), and $\delta \mathrm{SRH}$ (change in selfrated health over time).

At baseline, self-rated health was on average 6.84, and increased at follow-up to an average of 7.58. Change in self-rated health between baseline and follow-up had an average of 0.8056 , meaning that the average participant improved by nearly a whole point in self-rated health over time.

Assumptions of normality were tested for, and met. In accordance with our theoretical predictions, we first investigated univariate correlations between purported predictors (age, gender, non-age-adjusted co-morbidity index (NACI), activities of daily living (ADL), instrumental activities of daily living (IADL), education level, social support network (LSNS), loneliness (DJ T), neuroticism, extraversion, depression (CESD 8), anxiety (HADS A), 
Table 2. Stepwise multiple linear regression analysis, with selfrated health at baseline as dependent variable, and age, gender, non-age-adjusted co-morbidity index, neuroticism, extraversion, education level, social support (LSNS), ADL, IADL, PSS, depression, anxiety, loneliness, smoking and TMT (B-A) as predictors.

\begin{tabular}{lrcrrrr}
\hline & B & SE & Beta & t & Sig. & Tol. \\
\hline Constant & 7.972 & 0.175 & & 45.515 & 0.000 & \\
TMT B-A & -0.005 & 0.002 & -0.184 & -3.238 & 0.001 & 0.996 \\
DJ loneliness & 0.134 & 0.063 & 0.120 & 2.111 & 0.036 & 0.996 \\
\hline
\end{tabular}

perceived stress (PSS), executive functioning (TMT B A), smoking behaviour, frequency of alcohol intake, hours of physical exercise per week) and the dependent variable (self-rated health at baseline). Self-rated health was found to correlate significantly with smoking (rho $=-0.099$, $p<0.05$ ), ADL (rho $=-.19, p<0.001$ ), IADL (rho $=$ $0.326, p<0.001$ ), NACI (rho $=-0.311, p<0.001$ ), age (rho $=-0.221, p<0.001)$, education level (rho $=0.119$, $p<0.01$ ), neuroticism (rho $=-0.272, p<0.001$ ), extraversion (rho $=0.158, p<0.01)$, CESD 8 (rho $=-0.311$, $p<0.001$ ), HADS (rho $=-0.259, p<0.001$ ), DJ T $(-0.191, p<0.001$ ), LSNS (rho $=0.164, p<0.001$ ), PSS (rho $=-0.292, p<0.001$ ) and TMT B-A (rho $=$ $-0.168, p<0.001)$. Thus these were included as predictors in the regression model, and hours of physical exercise per week, and alcohol intake were excluded from the analyses.

We then performed a multiple regression analysis, with self-rated health at baseline as the dependent variable, and age, gender, non-age-adjusted co-morbidity index (NACI), activities of daily living (ADL), instrumental activities of daily living (IADL), education level, social support network (LSNS), loneliness (DJ T), neuroticism, extraversion, depression (CESD 8), anxiety (HADS A), perceived stress (PSS), executive functioning (TMT B - A), smoking behaviour, as predictor variables, at a cross-sectional level. This model was shown to be significant $\left[\mathrm{F}_{2,298}=7.944\right.$, $p<0.001$; adjusted $\left.R^{2}=0.045\right]$. Loneliness scores (DJ T) and TMT (B-A), a measure of executive function, were the only measures shown to significantly predict self-rated health status (see Table 2). Collinearity was examined and no values were found to be of concern (see tolerance values in Table 2).

A second multiple regression analysis was conducted with change in self-rated health over time $(\delta \mathrm{SRH})$ as the dependent variable and the same independent variables as before, was performed. This model was also shown to be significant $\left[\mathrm{F}_{1,249}=4.05, p<0.05\right.$; adjusted $\left.R^{2}=0.012\right]$. In this model, only TMT (B-A) was shown to be a significant predictor of $\delta$ SRH (see Table 3).

\section{Discussion}

We found that executive functioning and loneliness, in the absence of any other demographic, biological or psychosocial factors, predicted self-rated health in both crosssectional and longitudinal models. Overall, there was a change in self-rated health over time. On average,
Table 3. Backwards multiple linear regression with delta selfrated health (between baseline and follow-up) as dependent variable, and age, gender, non-age-adjusted co-morbidity index, neuroticism, extraversion, TMT (B-A), education, social support (LSNS), loneliness, ADL, IADL, perceived stress, smoking, anxiety and depression as predictors.

\begin{tabular}{lcccrc}
\hline & B & SE & Beta & t & Sig. \\
\hline Constant & 1.24 & 0.259 & & 4.784 & 0.000 \\
TMT (B-A) & -0.006 & 0.003 & -0.127 & -2.014 & 0.045 \\
\hline
\end{tabular}

participants improved by nearly a point on the ten-point self-rated health scale. This runs contrary to previous findings that stated that self-rated health should decline over time (Sargent-Cox et al., 2010). The relationship between executive function and self-rated health also runs contrary to previous findings (Rouch et al., 2014).

There are a number of limitations to the current study design. We did not account for potential intervention effects of the clinic programme. It is possible that participation in the clinic research programme represented an intervention since participants were referred on for any health problems detected during the course of the assessment. This was not recorded in any systematic fashion, as it was not related to the stated aims of the research, but the psychiatrist and geriatrician involved in the clinic programme averred that any medical or psychiatric issue detected during the assessment was dealt with by referral, as constituting a responsible care pathway. Reported reasons for referral included blood pressure maintenance, skin lesions, depressive symptomatology, and potential osteoarthritis. These referrals would have potentially led to the reported increase in participants' self-rated health, if the health check led to changes in health behaviour.

Furthermore, caution must be exercised to avoid overstating the results, since there was only a $6 \%$ increase in the amount of variance accounted for by the model, in the cross-sectional analysis, when executive functioning was added as a predictor. This variance accounted for fell to $1 \%$ in the longitudinal analysis. Executive functioning therefore appears to play a statistically significant, yet clinically minimal role in predicting self-rated health at a cross-sectional and longitudinal level. It is possible of course that the associations are caused by a confounding but uncontrolled variable in this study, rather than being driven by a causal relationship between executive function and self-rated health. More comprehensive modelling would be required to address this concern.

There are methodological limitations to the current study. The sample participating were a convenience sample of community-dwelling older adults from the hospital catchment area, and as such represent a healthy group of older adults. Therefore, the findings are not generalisable to a more frail population of older adults. Also, all participants were cognitively intact. Results cannot, then, be extrapolated to a dementia population, which is important considering that the topic in question is executive functioning. Executive dysfunction is thought to be a key factor in cognitive impairment. Therefore, results within a dementia population could deviate significantly from the 
current results. Since it has been suggested that the selfrated health measure is informative only in a nonimpaired population, it may not be possible to investigate the association between self-rated health and more advanced executive dysfunction in an older population. Further research could consider this issue.

Due to the low variance accounted for by the current study, we still cannot make conclusions about the causal bases of self-rated health; it is likely that the current analyses omitted significant predictors of this factor. This is an unexpected conclusion since we included a large number of potential factors in the model, relating to both health and psychosocial wellbeing. Furthermore, the high sample size means that the study may have been overpowered to find significant relationships in the absence of accounting for a reasonable amount of variance. However, we must reiterate that our samples were convenient and not representative of the general population and therefore all conclusions are tentative in nature.

We measured executive function using the trail making test. While, as stated, this test has previously been used as an index of executive functioning, its sole use in this study may limit interpretation since our assessment of executive function was therefore not holistic. Future studies could investigate executive functioning more comprehensively to investigate whether particular aspects of function are specifically related to self-rated health status.

Aside from loneliness, none of the psychosocial variables investigated appeared to predict self-rated health. This runs contrary to previous findings mentioned above, which found relationships between all psychosocial factors investigated in the current analyses, and self-rated health status (Alexopoulos et al., 2002; Duberstein et al., 2003; Liavaag et al., 2009; Nummela et al., 2011; Sturm \& Willmes, 2001; White et al., 2009). It is possible that the relationship between self-rated health and psychosocial well-being was in fact mediated by executive functioning, which would explain why no more of these variables are significant in the current models, where executive functioning is included. This possibility would indicate that for further research into the longitudinal relationship between executive functioning and self-rated health, a more sophisticated analytic approach, such as structural equation modelling, may be recommended.

Furthermore, while personality has previously been linked to self-rated health, in this previous analysis the 'Big Five' personality traits were assessed, while in our data-set we only had access to measurements of two personality traits - extraversion and neuroticism. A more holistic assessment of the relationship between executive function and self-rated health might control for all five personality variables. In our analysis neither trait included did account for any variance in the outcome, so it is hard to comment upon the inclusion of other personality traits and any changes to the current results that they might bring.

The current findings suggest that levels of executive functioning status appear to be related to self-rated health status, which may suggest that individuals use executive systems to make this judgement about their health. We did not find an association between objective health measures (the comorbidity index) and executive function - this would further support our conclusion that the association between executive function and self-rated health arises from the fact that we use the former to arrive at a judgement of the latter.

We failed to support the theories put forward by Sargent-Cox et al. (2010) or Han et al. (2005) since self-rated health actually improved over time, although this is potentially more compatible with Han's theory that self-rated health is a temporally contingent measurement and takes into account the individual's well-being as an interaction of relevant indicators at a given point in time.

The relationship between loneliness and self-rated health is in keeping with previous research findings (Nummela et al., 2011). These authors found evidence in longitudinal analyses for a causal role of loneliness in predicting self-rated health, although mechanisms by which this happens are unclear. Our findings were crosssectional in nature and we failed to find evidence of a longitudinal association between loneliness and self-rated health, suggesting that there may be an association but the directionality of causation is not clear.

The current findings have important implications for the health and functional status of older adults. Self-rated health is known to be a clinically relevant metric, often predicting outcome even over the predictive value of objective health metrics. Therefore, it is important to investigate whether self-rated health can be improved, in conjunction with attempts to improve underlying physical and psychosocial health, since this could then potentially mitigate the effects of poor self-rated health status on functional outcome, morbidity and mortality.

In conclusion, we report an independent association between executive functioning and loneliness, and selfrated health status, and between executive functioning and changes in self-rated health status over time. The relationship may be causal in nature since these data are longitudinal, although one must be mindful of the low variance accounted and the relationship was not confounded by demographic, biological or psychosocial variables. The current findings have implications for the maintenance of self-rated health and independent living in older adults in that executive function appears to be a legitimate target for intervention in this regard.

\section{Acknowledgements}

The authors would like to thank the participants and staff of the TRIL centre at St James's Hospital in Dublin. This work was supported by Intel Ireland, G.E. Healthcare and IDA Ireland as part of the TRIL (Technology Research for Independent Living) grant.

\section{Disclosure statement}

No potential conflict of interest was reported by the authors.

\section{Funding}

This work was supported by Intel Ireland, G.E. Healthcare and IDA Ireland as part of the TRIL (Technology Research for Independent Living) grant. 


\section{References}

Albert, M.S., \& Kaplan, E. (1980). Organic implications of neuropsychological deficits in the elderly. In F. Poon (Ed.), New directions in memory and aging (pp. 403-432). Hillsdale, NJ: Lawrence Erlbaum Associates.

Alexopoulos, D.S., \& Kalaitzidis, I. (2004). Psychometric properties of the eysenck personality questionnaire revised (EPQ-R) short scale in Greece. Personality and Individual Differences, 37(6), 1205-1220. doi: 10.1016/j.paid.2003.12. 005

Alexopoulos, G.S., Kiosses, D.N., Klimstra, S., Kalayam, B., \& Bruce, M. (2002). Clinical presentation of the 'depressionexecutive dysfunction syndrome' of late life. American Journal of Geriatric Psychiatry, 10(1), 98-106. doi:10.1176/appi.ajgp.10.1.98

Anstey, K., \& Christensen, H. (2000). Education, activity, health, blood pressure and Apolipoprotein E as predictors of cognitive change in old age: A review. Gerontology, 46(3), 163-177. doi:10.1159/000022153

Anstey, K., Stankov, L., \& Lord, S. (1993). Primary aging, secondary aging, and intelligence. Psychology \& Aging, 8(4), 562-570. doi:10.1037/0882-7974.8.4.562

Anstey, K.J., Luszcz, M.A., Giles, L.C., \& Andrews, G.R. (2001). Demographic, health, cognitive and sensory variables as predictors of mortality in very old adults. Psychology and Aging, 16(1), 3-11. doi:10.1037/0882-7974.16.1.3

Arbuthnott, K., \& Frank, J. (2000). Trail making test, part B, as a measure of executive control: Validation using a set-switching paradigm. Journal of Clinical Experimental Neuropsychology, 22(4), 518-528. doi: 10.1076/1380-3395(200008) 22:4;1-0;FT518

Burke, K., Schnittger, R., O’Dea, B., Buckley, V., Wherton, J.P., \& Lawlor, B.A. (2011). Factors associated with perceived health in older adult Irish populations. Aging \& Mental Health, 16(3), 288-295. doi:10.1080/13607863.2011.628976

Cahn-Weiner, D.A., Boyle, P.A., \& Malloy, P.F. (2002). Tests of executive function predict instrumental activities of daily living in community-dwelling older individuals. Applied Neuropsychology, 9(3), 187-191. doi:10.1207/S15324826AN0903_8

Carmelli, D., Swan, G.E., LaRue, A., \& Eslinger, P.J. (1997). Correlates of change in cognitive function in survivors from the Western Collaborative Group Study. Neuroepidemiology, 16(6), 285-295. doi:10.1159/000109699

Charlson, M., Pompei, P., Ales, K., \& MacKenzie, C. (1987). A new method of classifying prognostic comorbidity in longitudinal studies: Development and validation. Journal of Chronic Diseases, 40(5), 373-383. doi:10.1016/0021-9681 (87) $90171-8$

Cohen, S., \& Williamson, G. (1988). Perceived stress in a probability sample of the U.S. In S. Spacapam \& S. Oskamp (Eds.), The social psychology of health: Claremont symposium on applied social psychology. Newbury Park, CA: Sage.

Cohen, S., Kamarck, T., \& Mermelstein, R. (1983). A global measure of perceived stress. Journal of Health and Social Behaviour, 24(4), 385-396. doi:10.2307/2136404

Cullen, B., Fahy, S., Cunningham, C.J., Coen, R.F., Bruce, I., Greene, E., ... Lawlor, B.A. (2005). Screening for dementia in an Irish community sample using MMSE: A comparison of norm-adjusted versus fixed cut-points. International Journal of Geriatric Psychiatry, 20(4), 371-376. doi:10.1002/ gps. 1291

de Jong Gierveld, J., \& Tilburg, T. (2006). A six-item scale for overall, emotional and social loneliness: Confirmatory tests on survey data. Research on Aging: A Bimonthly on Aging and the Life Course, 28(5), 582-598. doi:10.1177/ 0160427506289723

DeSalvo, K.B., Bloser, N., Reynolds, K., He, J., \& Muntner, P. (2006). Mortality prediction with a single general self-rated health question. Journal of General Internal Medicine, 21 (3), 267-275. doi:10.1111/j.1525-1497.2005.00291.x
Duberstein, P.R., Sorensen, S., Lyness, J.M., King, D.A., Conwell, Y., Seidlitz, L., \& Caine, E.D. (2003). Personality is associated with perceived health and functional status in older primary care patients. Psychology and Aging, 18(1), 25-37. doi:10.1037/0882-7974.18.1.25

Earles, J.L.K., Conner, L.T., Smith, A.D., \& Park, D.C. (1997). Interrelations of age, self-reported health, speed and memory. Psychology and Aging, 12(4), 675-683. doi:10.1037/ 0882-7974.12.4.675

Eysenck, H., \& Eysenck, S. (1991). Eysenck personality questionnaire, revised (EPQ-R). London: Hodder \& Stoughton.

Fals-Stewart, W. (1992). An inter-rater reliability study of the trail making tests (parts A and B). Perceptual and Motor Skills, 74(1), 39-42. doi:10.2466/pms.1992.74.1.39

Folstein, M. F., Folstein, S. E., \& McHugh, P. R. (1975). Mini mental state: A practical method for grading the cognitive state of patients for the clinician. Journal of Psychiatric Research, 12(13), 189-198.

Fried, L.P., Tangen, C.M., Walston, J., Newman, A.B., Hirsch, C., Gottdiener, J., \& McBurnie, M.A. (2001). Frailty in older adults: Evidence for a phenotype. Journals of Gerontology A: Biological Sciences and Medical Sciences, 56(3), 146-157.

Gaudino, E.A., Geisler, M.W., \& Squires, N.K. (1995). Construct validity in the trail making test: What makes part B harder? Journal of Clinical and Experimental Neuropsychology, 17(4), 529-535. doi:10.1080/01688639508405143

Grigsby, J., Kaye, K., Baxter, J., Shetterly S.M., \& Hamman, R.F. (1998). Executive cognitive abilities and functional status among community-dwelling older persons in the San Luis Valley Health and Aging study. Journal of the American Geriatrics Society, 46(5), 590-596.

Han, B., Phillips, C., Ferrucci, L., Bandeen-Roche, K., Jylha, M., Kasper, J., \& Guralnik, J. (2005). Change in self-rated health and mortality among community-dwelling disabled older women. The Gerontologist, 45(2), 216-221. doi:10.1093/ geront $/ 45.2 .216$

Hultsch, D., Hammer, M., \& Small, B.J. (1993). Age differences in cognitive performance in later life: Relationships to selfreported health and activity lifestyle. Journal of Gerontology, 48(1), 1-11. doi:10.1093/geronj/48.1.P1

Idler, E.L., \& Benyamini, Y. (1997). Self-rated health and mortality: A review of 27 community studies. Journal of Health and Social Behaviour, 38(1), 21-37.

Idler, E.L., \& Kasl, S.V. (1995). Self-ratings of health: Do they also predict change in functional ability? Journal of Gerontology B: Psychological Sciences and Social Sciences, 50 (6), 344-353. doi:10.1093/geronb/50B.6.S344

Juerges, H., Avendano, M., \& Mackenbach, J. (2007). How comparable are different measures of self-rated health? (Evidence from five European countries, MEA Discussion Paper 137-2007). University of Mannheim. doi: 10.2139/ssrn.144 5365

Kaplan, G.A., Goldberg, D.E., Everson, S.A., Cohen, R.D., Salonen, R., Tuomiletho, J., \& Salonen, J. (1996). Perceived health status and morbidity and mortality: Evidence from the Kuopio ischaemic heart disease risk factor study. International Journal of Epidemiology, 25(2), 259-265. doi:10.1093/ije/25.2.259

Kubzansky, L.D., Buka, S.L., \& Martin, L.T. (2009). Early manifestation of personality and adult health: A life course perspective. Health Psychology, 28(3), 364-372. doi:10.1037/ a0014428

Kuo, H.K., \& Lipsitz, L.A. (2004). Cerebral white matter changes and geriatric syndromes: Is there a link? Journal of Gerontology A: Biological Sciences and Medical Sciences, 59(8), 818-826. doi:10.1093/gerona/59.8.M818

Lawton, M.P., \& Brody, E.M. (1969). Assessment of older people: Self-maintaining and instrumental activities of daily living. Gerontologist, 9(3), 179-186. 
Lezak, M., Howieson, D., \& Loring, D. (2004). Neuropsychological assessment (4th ed.). New York, NY: Oxford University Press.

Liavaag, A.H., Dorum, A., Fossa, S.D., Trope, C., \& Dahl, A.A (2009). Morbidity associated with 'self-rated health' in epithelial ovarian cancer survivors. BMC Cancer, 9(2). doi:10.1186/1471-2407-9-2

Lubben, J., \& Gironda, M. (2004). Measuring social networks and assessing their benefits. In C. Phillipson, G. Allan, \& D. Morgan (Eds.), Social networks and social exclusion: Sociological and policy perspectives. Keele: Ashgate.

Lubben, J., Blozik, E., Gilmann, G., Iliffe, S., Renteln Kruse, W., Beck, J.C., \& Stuck, A.E. (2006). Performance of an abbreviated version of the Lubben social network scale among three European community-dwelling older adult populations. The Gerontologist, 46(4), 503-513. doi:10.1093/geront $/ 46.4 .503$

Nummela, O., Soppanen, M., \& Uutela, A. (2011). The effect of loneliness and change in loneliness in self-rated health (SRH): A longitudinal study among aging people. Archives of Gerontology and Geriatrics, 53(2), 163-167. doi: 10.1016/j.archger.2010.10.023

Radloff, L. (1977). The CES-D scale: A self-report depression scale for research in the general population. Applied Psychological Measurement, 1(3), 385-401. doi:10.1177 014662167700100306

Romero-Ortuno, R., Cogan, L., Fan, C.W., \& Kenny, R.A. (2010). Intolerance to initial orthostasis relates to systolic BP changes in elders. Clinical Autonomic Research, 20(1), $39-45$.

Rouch, I., Achour-Crawford, E., Roche, F., Castro-Lionard, C., Laurent, B., Ntougou Assoumou, G.,... Trombert, B. (2014). Seven year predictors of self-rated health and life satisfaction in the elderly: The PROOF study. Journal of Nutrition, Health \& Aging, 18(9), 840-847.

Salthouse, T.A., Atkinson, T.M., \& Berish, D.E. (2003). Executive functioning as a potential mediator of age-related cognitive decline in normal adults. Journal of Experimental Psychology: General, 132(4), 566-594. doi:10.1037/00963445.132.4.566

Salthouse, T.A., Kausler, D.H., \& Saults, J.S. (1990). Age, selfassessed health status, and cognition. Journal of Gerontology: Psychological Sciences, 45(4), 156-160. doi:10.1093/ geronj/45.4.P156

Sargent-Cox, K.A., Anstey, K.J., \& Luszcz, M.A. (2010). Patterns of longitudinal change in older adults' SRH: The effect of the point of reference. Health Psychology, 29(2), 143-152. doi:10.1037/a0017652

Singh-Manoux, A., Martikainen, P., Ferrie, J., Zins, M., Marmot, M., \& Goldberg, M. (2006). What does self-rated health measure? Results from the British Whitehall II and French Gazel cohort studies. Journal of Epidemiological Community Health, 60(4), 364-372. doi:10.1136/ jech.2005.039883

Sturm, W., \& Willmes, K. (2001). On the functional neuroanatomy of intrinsic and phasic alertness. Neuroimage, 14(1), 76-84. doi: 10.1006/nimg.2001.0839

Walker, J.D., Maxwell, C.J., Hogan, D.B., \& Ebly, E.M. (2004). Does self-rated health predict survival in older persons with cognitive impairment? Journal of the American Geriatrics Society, 52(11), 1895-2000. doi:10.1111/j.1532-5415.2004. 52515.x

White, A. Philgene, S., Fine, L., \& Sinha, S. (2009). Social support and self-reported health status of older adults in the United States. American Journal of Public Health, 99(10), 1872-1878. doi:10.2105/AJPH.2008.146894

Woolrich, R.A., Kennedy, P., \& Tasiemski, T. (2006). A preliminary psychometric evaluation of the hospital anxiety and depression scale (HADS) in 963 people living with a spinal cord injury. Psychology, Health and Medicine, 11(1), 80-90. doi:10.1080/13548500500294211

Zigmond, A., \& Snaith, R. (1983). The hospital anxiety and depression scale. Acta Psychiatrica Scandinavica, 67(6), 361-370. doi:10.1186/1477-7525-1-29 